\title{
Exposure to Carbonic Gas Enriched Atmosphere or Electrical Water Bath to Stun or Kill Chickens
}

\section{-Author(s)}

Nicolau JPI

Pinto MFI

Ponsano EHG

Perri SHV

Garcia Neto M

UNESP - Universidade Estadual Paulista "Júlio de Mesquita Filho", Faculdade de Medicina Veterinária de Araçatuba

\section{Mail Address}

Corresponding author e-mail address Juliana Pampana Nicolau

Rua Clóvis Pestana, 793, Araçatuba, São

Paulo, Brazil. Zip code: 16050-680

Phone: 55 (14) 997150326

E-mail: julianapampana@yahoo.com.br

\section{-Keywords}

Animal welfare, broiler, meat characteristic, slaughter, stunning.

\section{ABSTRACT}

The objective of this study was to compare the effects of two methods (electrical water bath or carbonic gas atmosphere) for stunning or killing broiler chickens prior to bleeding on weight loss due to bleeding and meat traits. A completely randomized design with $2 \times 2$ factorial arrangement (electrical or gas system $\times$ stunning or killing) was applied. The time required for stunning and killing and the birds' behavior were evaluated for the gas exposure method. The birds killed by the electrical method retained more blood than those killed by the exposure to gas and, therefore, presented redder meat. The exposure to 10 to $15 \% \mathrm{CO}_{2}$ atmosphere caused discomfort reactions in $100 \%$ of birds, and the intensity of reaction presented a wide variation: $35 \%$ for weak reaction, $40 \%$ for intermediate reaction, and $25 \%$ for strong reaction. The time required to stun or kill the birds by $\mathrm{CO}_{2}$ exposure varied from 28 to 97 seconds and from 42 to 158 seconds, respectively. It was concluded that the time required to stun or to kill the birds by $\mathrm{CO}_{2}$ exposure widely varied and caused discomfort reactions; however, meat traits were not influenced by the methods used in this experiment.

\section{INTRODUCTION}

Reducing the suffering of animals at slaughter is becoming an important quality attribute for an increasing share of the meat consumer market. Brazilian legislation requires the stunning of animals before bleeding (Brasil, 1998; Brasil, 2000).

In Brazil, as well as in other countries where broiler slaughter is automated, birds are stunned in electrical water bath systems. In this method, the steps prior to electric stunning cause clear discomfort to the birds. During hanging, for instance, there must be maximum contact of the birds' legs with the metal shackle to allow effective application of the electrical current, which means that, depending on broiler size, the feet must be forced into the hooks.

Moreover, the upside down position can cause birds to flap their wings due to fear and discomfort, resulting in distress, suffering, and injuries (Ludtke et al., 2010). Other disadvantages are the difficulty to adjust the equipment to the size of the birds, the occurrence of preshocks, inadequate bird positioning, and ineffective stunning.

Some research studies suggest the exposure to controlled atmosphere to replace the electrical systems, either to stun or kill broiler chickens (Raj \& Gregory, 1990; Kang \& Sams, 1999; Gerritzen et. al., 2000). According to those studies, the exposure of birds to air containing high levels of carbon dioxide caused anesthesia and showed good results. However, carbon dioxide is acidic and irritates mucous membranes during inhalation, causing birds to immediately 
stop breathing before the loss of consciousness. Nevertheless, according to Raj \& Gregory (1990) and Raj (1998), killing broiler chickens by exposure to controlled atmosphere may minimize their suffering at slaughter.

This study investigated meat traits and weight loss due to bleeding when the birds were stunned or killed by either electrical water bath immersion or by $\mathrm{CO}_{2}$ exposure. The time required to stun and to kill the broilers, as well as their behavior when submitted to $\mathrm{CO}_{2}$ exposure were also evaluated.

\section{MATERIAL AND METHODS}

Forty 42-day-old male Cobb 500 broilers were divided into four groups of 10 birds each. Birds were individually identified, weighed and transported to the experimental pilot scale abattoir. Each group was submitted to one of the following treatments: 1) electrical stunning (electronarcosis); 2) electrical killing (electrocution); 3) $\mathrm{CO}_{2}$ stunning, or 4) $\mathrm{CO}_{2}$ killing

The experiment followed a completely randomized design in a $2 \times 2$ factorial arrangement (electrical or gas system $x$ stunning or killing) with 10 replicates per treatment. Parameters were evaluated per individual bird, and therefore, each bird was considered as an experimental unit for the analysis of variance (Perret, 2012). The slaughter procedures were performed according to the Brazilian legislation (Brasil, 1998).

\section{Electrical method}

A pilot scale electrical equipment, consisting of overhead rails with metal shackles to hang the birds and an electrified water bath, with capacity to apply electric current to one bird at a time, was used. The electrical current parameters were fixed at $240 \mathrm{~V} \mathrm{AC}$, $60 \mathrm{~Hz}$, and $120 \mathrm{~mA}$. Therefore, the only parameter that was changed in order to cause electronarcosis or electrocution was the exposure time of the bird to electric current. The electrical stunning was performed by immersing the bird's head for 3 seconds in electrified water to produce effective unconsciousness. Birds were considered stunned when both nictitating membrane reflex and rhythmic breathing were absent. Rhythmic breathing was indicated by contraction of the abdominal muscles near the cloaca (Ludtke et al., 2010).

In order to kill the broilers by the electrical method, the bird's head was immersed in electrified water for 8 to 10 seconds, until death, as confirmed by the observation of the complete respiratory arrest.

\section{CO2 exposure method}

The birds were exposed to $\mathrm{CO}_{2}$ enriched atmosphere in a pilot scale stainless steel experimental chamber with acrylic ceiling, in order to allow the observation of birds' behavior, attached to a $\mathrm{CO}_{2}$ gas cylinder. $\mathrm{CO}_{2}$ concentration was monitored by a Scenty GDZ 203 HTK Hamburg GMBH gas analysis system, equipped with a $760 \mathrm{GMF} 0$ to $100 \% \mathrm{CO}_{2}$ sensor inside the chamber. The Brazilian legislation determines a minimum $\mathrm{CO}_{2}$ concentration of $30 \%$ for the stunning of chickens (Brasil, 2000). However, according to Bitencourt (2011), birds suddenly submitted to this $\mathrm{CO}_{2}$ level may show agitation and/or convulsive reactions. Therefore, this experiment used an initial 10\% $\mathrm{CO}_{2}$ concentration, which was gradually increased until the bird was completely stunned, at approximately $13 \% \mathrm{CO}_{2}$. Birds were individually placed inside the chamber. Prior to each new stunning procedure, the gas concentration was set back to $10 \%$. The broilers were considered stunned when they fell and did not present any rhythmic breathing movement or nictitating membrane reflex.

The same procedures were carried out to kill the birds. In this case, however, the bird was maintained in the chamber until it died, as confirmed by complete respiratory arrest, which happened at a $\mathrm{CO}_{2}$ concentration of approximately $15 \%$.

\section{Behavior Evaluation of the Birds Exposed to $\mathrm{CO}_{2}$}

During the exposure to the $\mathrm{CO}_{2}$ atmosphere, the behavior of the birds before they fell was classified as "no reaction", when the bird presented only tachypnea; "weak reaction", when the bird gasped and/or shook its head, "intermediate reaction", when the bird presented weak and intermittent wing flapping; and "strong reaction", when the bird presented continuous and strong wing flapping.

\section{Weight Loss after Bleeding}

All birds were individually weighed, bled immediately after stunning or killing by either electrical or gas treatment, and then weighed again to determine weight loss due to bleeding, expressed as a percentage of live weight.

\section{Meat pH}

Breast and thigh meat $\mathrm{pH}$ was determined 24 hours after slaughter using a pHmeter (Mettler Toledo Model $1120-X)$ with a penetrating probe. 


\section{Meat Color}

Breast and thigh meat color was evaluated after the skin was removed and in triplicate, using Hunterlab Miniscan XE Plus with D65 illuminant and $10^{\circ}$ observation angle. Color was expressed according to the CIELab color system, which attributes L* (lightness), ranging from zero (absolute black) to 100 (absolute white); $a^{*}$, ranging from green (negative values) to red (positive values); and $b^{*}$, ranging from blue (negative values) to yellow (positive value) (Minolta, 2007).

The equipment was positioned on the dorsal surface of the breast fillet and on the lateral surface of the thighs, avoiding hemorrhagic petechiae, discolored spots, and any other color interference.

\section{Statistical Analysis}

The results were submitted to analysis of variance and means were compared by Duncan's test at $5 \%$ significance level. Pearson's linear correlation coefficient among variables was determined (Zar, 2009). Statistical analyses were performed using the Statistical Analysis System (SAS, 2008).

\section{RESULTS AND DISCUSSION}

Broilers submitted to gas method presented lower and higher meat redness and lightness values, respectively, compared with those of broilers submitted to the electrical method ( $p<0.05$ ), probably due to the smaller amount of residual blood in the muscles, as shown by the significantly lower weight loss due to bleeding of the birds submitted to the electrical method (Table 1).

The birds killed by the electrical method presented higher thigh meat $\mathrm{pH}$ compared with those in the other treatments (Table 2). This may be explained by the longer time of exposure of the birds to electricity, causing muscle contraction and depletion of muscle energy reserves (Judge, 1989). As muscle glycogen stores are depleted, less lactic acid is produced, and consequently lower muscle $\mathrm{pH}$ decrease after slaughter.

Weight loss due to bleeding was not different between broilers stunned and killed by either of the methods applied (electrical and gas). However, when both methods are compared, electrically killed broilers lost significantly less weight after bleeding than those

Table 1 - Weight loss due to bleeding and breast and thigh meat traits of broilers submitted to electrical or gas stunning or killing.

\begin{tabular}{|c|c|c|c|c|c|c|c|c|c|}
\hline \multirow{3}{*}{ Factors } & \multicolumn{9}{|c|}{ Parameters } \\
\hline & \multirow{2}{*}{ Weight loss due to bleeding (\%) } & \multicolumn{2}{|c|}{$\mathrm{pH}$} & \multicolumn{2}{|c|}{$L^{* 1}$} & \multicolumn{2}{|c|}{$a^{* 2}$} & \multicolumn{2}{|c|}{$b^{* 3}$} \\
\hline & & Breast & Thigh & Breast & Thigh & Breast & Thigh & Breast & Thigh \\
\hline \multicolumn{10}{|c|}{ Methods (M) } \\
\hline Electrical & $2.65^{b}$ & 6.06 & 6.49 & $61.99^{b}$ & 61.96 & $5.51^{\mathrm{a}}$ & 6.83 & 14.95 & 13.21 \\
\hline Gas & $3.56^{\mathrm{a}}$ & 6.10 & 6.46 & $64.69^{a}$ & 63.48 & $4.47^{b}$ & 5.58 & 15.15 & 15.61 \\
\hline \multicolumn{10}{|c|}{ Procedures (P) } \\
\hline Stunning & 3.14 & 6.04 & $6.38^{b}$ & 62.75 & 62.06 & 5.06 & 5.59 & 15.78 & 13.45 \\
\hline Killing & 3.00 & 6.13 & $6.59^{a}$ & 63.93 & 63.38 & 4.92 & 6.82 & 14.32 & 15.38 \\
\hline \multicolumn{10}{|l|}{$P$ value } \\
\hline M & 0.0002 & 0.4907 & 0.6131 & 0.0266 & 0.2835 & 0.0131 & 0.2199 & 0.8413 & 0.4097 \\
\hline$P$ & 0.9269 & 0.1052 & 0.0009 & 0.3207 & 0.3508 & 0.7406 & 0.2239 & 0.1487 & 0.5057 \\
\hline$M \times P$ & 0.0111 & 0.5747 & 0.0216 & 0.0728 & 0.1224 & 0.0016 & 0.9849 & 0.4259 & 0.2267 \\
\hline $\mathrm{CV}(\%)^{4}$ & 21.62 & 2.80 & 2.54 & 5.84 & 7.07 & 25.18 & 50.95 & 20.79 & 63.04 \\
\hline
\end{tabular}

\footnotetext{
${ }^{a-c}$ Means followed by different letters in the column are significantly different by Duncan's test $(p<0.05) .1=$ lightness; $2=$ redness; $3=$ yellowness; $4=$ coefficient of variation
} 
killed by gas exposure. This may be explained by the application of $120 \mathrm{~mA}$ electrical current, which can cause the rupture of intramuscular blood vessels and blood retention in muscle tissue (Gregory \& Austin, 1992; Lambooij et. al., 1999).

Table 2 - Deployment of the interactions among treatments for weight loss due to bleeding, thigh meat $\mathrm{pH}$, and breast meat redness.

\begin{tabular}{llccc}
\hline & & \multicolumn{3}{c}{ Parameters } \\
\cline { 3 - 5 } Methods & Procedures & $\begin{array}{l}\text { Weight loss due } \\
\text { to bleeding (\%) }\end{array}$ & Thigh pH & $\begin{array}{l}\text { a (breast } \\
\text { redness) }\end{array}$ \\
\hline \multirow{2}{*}{ Electric } & Killing & $2.41^{\mathrm{c}}$ & $6.66^{\mathrm{a}}$ & $6.12^{\mathrm{a}}$ \\
& Stunning & $2.97^{\mathrm{bc}}$ & $6.33^{\mathrm{c}}$ & $4.90^{\mathrm{b}}$ \\
Gas & Killing & $3.89^{\mathrm{a}}$ & $6.50^{\mathrm{b}}$ & $3.73^{\mathrm{c}}$ \\
\hline & Stunning & $3.30^{\mathrm{ab}}$ & $6.43^{\mathrm{bc}}$ & $5.21^{\mathrm{ab}}$ \\
\hline
\end{tabular}

${ }^{a-c}$ Means followed by different letters in the same column are significantly different by Duncan's test $(p<0.05)$.

The influence of the amount of blood drained from the carcasses on meat redness is confirmed by Pearson's correlation results, shown in Tables 3 and 4. There was a negative correlation between these parameters, indicating that the greater the weight loss caused due to bleeding, the lower was the a value. A higher and more significant correlation was found for thigh meat, which redness is more intense due to a higher concentration of myoglobin and to a more developed vascular system compared with breast muscles (Varnam \& Sutherland, 1995). A significant correlation between breast and thigh meat $\mathrm{pH}$ and $b$ values was also observed. However, considering that the breast meat $\mathrm{pH}$ values were not different between treatments, it is not possible to associate these results with the method of stunning or killing.

Table 3 - Pearson's correlation coefficients for breast meat parameters

\begin{tabular}{lcccc}
\hline & $\mathrm{pH}$ & $\mathrm{L}^{* 1}$ & $\underline{a}^{* 2}$ & $\mathrm{~b}^{* 3}$ \\
\hline $\begin{array}{l}\text { Weight loss due } \\
\text { to bleeding }\end{array}$ & 0.2259 & 0.0872 & -0.4580 & -0.1622 \\
$\mathrm{p}$-value & 0.3673 & 0.7307 & 0.0560 & 0.5201 \\
$\mathrm{pH}$ & & -0.1053 & -0.1986 & -0.4715 \\
$\mathrm{p}$-value & & 0.6775 & 0.4294 & 0.0482 \\
$\mathrm{~L}^{*}$ & & & -0.4086 & 0.0626 \\
$\mathrm{p}$-value & & & 0.0923 & 0.8050 \\
$a^{*}$ & & & & 0.2514 \\
$\mathrm{p}$-value & & & & 0.3142 \\
\hline
\end{tabular}

${ }^{1}=$ lightness $^{2}{ }^{2}=$ redness; ${ }^{3}=$ yellowness.
Table 4 - Pearson's correlation coefficient for thigh meat parameters

\begin{tabular}{lcccc}
\hline & $\mathrm{pH}$ & $L^{1}$ & $a^{2}$ & $b^{3}$ \\
\hline $\begin{array}{l}\text { Weight loss due } \\
\text { to bleeding }\end{array}$ & -0.2767 & 0.1072 & -0.6809 & -0.0926 \\
p-value & 0.2662 & 0.6721 & 0.0019 & 0.7147 \\
pH & & -0.1226 & 0.4494 & -0.5230 \\
p-value & & 0.6280 & 0.0613 & 0.0259 \\
\hline L & & & -0.2865 & 0.2414 \\
p-value & & & 0.2490 & 0.3346 \\
a & & & & 0.1037 \\
p-value & & & & 0.6823 \\
\hline
\end{tabular}

${ }^{1}=$ lightness $^{2}=$ redness; $^{3}=$ yellowness.

According to Grandin (2010), there has been much controversy about the effect of different gases on bird discomfort during the induction of insensibility. This is why, in the present study, the initial $\mathrm{CO}_{2}$ concentration used was $10 \%$, and then was gradually increased after the birds were placed into the chamber. All birds reacted when exposed to $\mathrm{CO}_{2}$, both during the killing and the stunning procedures: $35 \%$ presented weak reaction, $40 \%$ intermediate reaction, and $25 \%$ strong reaction (Figure 1).

Bird's reaction on the exposure to $\mathrm{CO}_{2}(\%)$

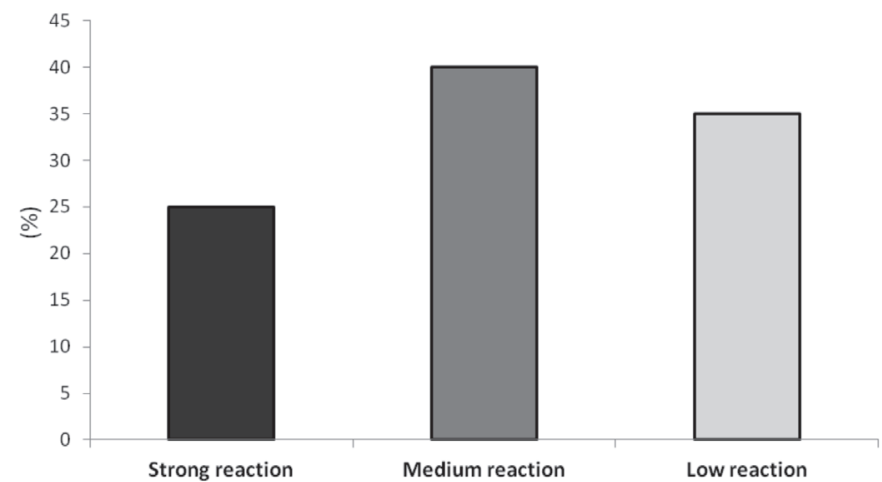

Figure 1 - Birds' reaction, in percentage, on the exposure to $\mathrm{CO}_{2}$.

The time required to stun and to kill the birds by the gas exposure method presented a wide variation, ranging from 28 to 97 seconds for stunning and from 42 to 158 seconds for killing. Under experimental conditions, birds' reactions to the gas may be different when compared with those observed in processing plants. Specific gas concentrations that can be easily maintained at laboratory scale may be difficult to maintain in commercial facilities (Grandin, 2010). Therefore, in practice, the adoption of gas stunning method presents some difficulties. 
The results of the present study demonstrated that the gas exposure method did not prevent bird discomfort and resulted in a wide variation in individual broilers' responses, precluding the standardization of the process parameters. Therefore, considering the high costs of installing and operating the method of gas exposure and the fact that most broiler processing plants operate with electrical equipment, it is suggested that investing in the optimization and standardization of the electrical equipment parameters is more feasible to reduce broiler suffering then implementing other stunning methods. Furthermore, electrical current parameters may be set to kill he birds, which would bring undeniable welfare benefits, reduce the occurrence of conscious birds at bleeding and the possibility of birds get drowned in water baths in the case of possible interruptions in the slaughter line.

\section{CONCLUSIONS}

It was demonstrated that the exposure of broilers to 10 to $15 \% \quad \mathrm{CO}_{2}$ atmosphere is an inefficient technological alternative to reduce suffering. In addition, it is an unfeasible industrial application due to the wide variation in the time required to stun or to kill the birds. Killing poultry both by the methods of electrical water bath and exposure to $\mathrm{CO}_{2}$, followed by immediate bleeding, did not cause any meat trait changes that may adversely affect product acceptance by the consumers.

\section{REFERENCES}

Bitencourt DA. Insensibilização de frangos de corte em atmosfera controlada na promoção do bem-estar animal [dissertação]. Araçatuba: Universidade Estadual Paulista Júlio de Mesquita Filho; 2011.

BRASIL. Ministério da Agricultura, Pecuária e Abastecimento. Portaria $n^{\circ}$ 210, de 10 de Novembro de 1998. Aprova o regulamento técnico de inspeção tecnológica e higiênico-sanitária de carne de aves. Diário Oficial da República Federativa do Brasil. Brasília, DF; 1998.
BRASIL. Ministério da Agricultura, Pecuária e Abastecimento. Instrução Normativa $n^{\circ} 3$, de 17 de Janeiro de 2000. Aprova o regulamento técnico de métodos de insensibilização para o abate humanitário de animais de açougue. Diário Oficial da República Federativa do Brasil. Brasília, DF; 2000

Gerritzen MA, Lambooij E, Hillebrand SJW, Lankhaar JAC, Pieterse C. Behavioral responses of broilers to different gaseous atmospheres. Poultry Science 2000;79(6): 928-33.

Grandin T. Animal welfare e evaluation of gas stunning (controlled atmosphere stunning) of chickens and other poultry [cited 2012]. Fort Collins: Colorado State University, Department of Animal Science; 2012. Available from: http://www.grandin.com/gas.stunning.poultry. eval.html.

Gregory NG, Austin SD. Causes of trauma in broilers arriving dead at poultry processing plants. Veterinary Record 1992;131(22):501-3.

Judge MD. Principles of meat science. lowa: Kendall Hunt Publishing Company; 1989.

Kang IS, Sams AR. A comparison of texture and quality of breast fillets from broilers stunned by electricity and carbon dioxide on a shackle-line or killed by carbon dioxide. Poultry Science 1999;78(9):1334-7.

Konica Minolta Sensing, Inc. Precise color communication: color control from perception to instrumentation [cited 2013]. Chiyoda: Konica Minolta; 2007 Available from: http://www.konicaminolta.com/ instruments/knowledge/color/pdf/color_communication.pdf.

Lambooij E, Pieterse C, Hillebrand SJ, Dijksterhuis GB. The effects of captive bolt and electrical stunning, and restraining methods on broiler meat quality. Poultry Science 1999;78(4):600-7.

Ludtke CB, Ciocca JRP, Dandim T, Barbalho PC, Vilela JA. Abate humanitário de aves: steps melhorando o bem-estar animal no abate. Rio de Janeiro: WSPA; 2010.

Perret JJ. A case study on teaching the topic "experimental unit" and how it is presented in advanced placement statistics textbooks. Journal of Statistics Educations 2012;20(2):1-14

Raj ABM, Gregory NG. Investigation into the batch stunning/killing of chickens using carbon-dioxide or argon induced hypoxia. Research Veterinary Science 1990;49(3):364-6.

Raj M. Welfare during stunning and slaughter of poultry. Poultry Science $1997 ; 77: 1815-9$.

SAS Institute. SAS/STAT 9.2 user's huide. Cary; 2008.

Varnam AH, Sutherland JP. Meat and meat products. London: Chapman \& Hall; 1995.

Zar JH. Biostatistical analysis. $5^{\text {th }}$ ed. New Jersey: Prentice-Hall; 2009. 
